University of New Mexico

UNM Digital Repository

Shared Knowledge Conference

2018 Conference

Nov 7th, 3:00 PM - 4:00 PM

\title{
Demand Response Management in Smart Grid Networks: a Two-Stage Game-Theoretic Learning- Based Approach
}

Pavlos Athanasios Apostolopoulos

University of New Mexico, pavlosapost@unm.edu

Follow this and additional works at: https:// digitalrepository.unm.edu/skc

Part of the Other Electrical and Computer Engineering Commons, and the Systems and Communications Commons

Apostolopoulos, Pavlos Athanasios. "Demand Response Management in Smart Grid Networks: a Two-Stage Game-Theoretic

Learning-Based Approach." (2018). https://digitalrepository.unm.edu/skc/2018/posters/4

This Event is brought to you for free and open access by UNM Digital Repository. It has been accepted for inclusion in Shared Knowledge Conference

by an authorized administrator of UNM Digital Repository. For more information, please contact disc@unm.edu. 


\title{
Demand Response Management in Smart Grid Networks: a Two- Stage Game-Theoretic Learning-Based Approach
}

\author{
My name: Pavlos Athanasios Apostolopoulos \\ Other Authors: Eirini Eleni Tsiropoulou, Symeon Papavasiliou \\ Department of Electrical and Computer Engineering UNM
}

\begin{abstract}
In this paper, the combined problem of power company selection and demand response management (DRM) in a smart grid network consisting of multiple power companies and multiple customers is studied via adopting a reinforcement learning and game-theoretic technique. Each power company is characterized by its reputation and competitiveness. The customers, acting as learning automata select the most appropriate power company to be served, in terms of price and electricity needs' fulfillment, via a reinforcement learning based mechanism. Given customers' power company selection, the DRM problem is formulated as a two-stage game theoretic optimization framework. At the first stage the optimal customers' electricity consumption is determined and at the second stage the optimal power companies' pricing is obtained. The output of the DRM problem feeds the learning system to build knowledge and to conclude to the optimal power company selection. To realize the aforementioned framework a two-stage Power Company learning selection and Demand Response Management (PC-DRM) iterative algorithm is introduced. The performance evaluation of the proposed approach is achieved via modeling and simulation and its superiority against other approaches is illustrated.
\end{abstract}

